Document downloaded from:

http://hdl.handle.net/10251/112961

This paper must be cited as:

Sánchez-Correa, FV.; Vidaurre Agut, CM.; Serrano Aroca, A.; Campillo Fernandez, AJ. (2018). Poly(2-hydroxyethyl acrylate) hydrogels reinforced with graphene oxide: Remarkable improvement of water diffusion and mechanical properties. Journal of Applied Polymer Science. 135(15). doi:10.1002/app.46158

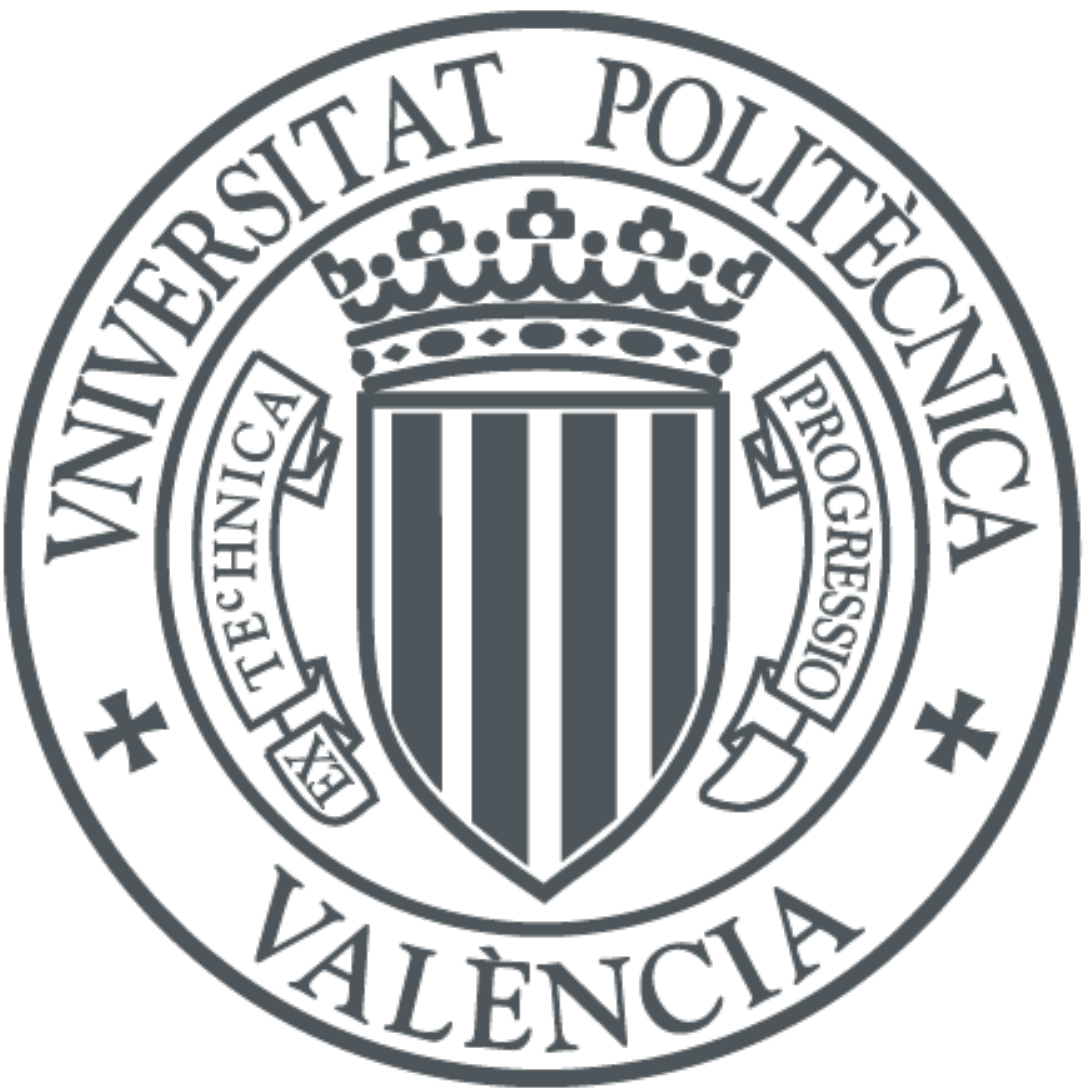

The final publication is available at https://doi.org/10.1002/app.46158

Copyright John Wiley \& Sons

Additional Information 


\section{Poly(2-hydroxyethyl acrylate) hydrogels reinforced with graphene oxide: remarkable improvement of water diffusion and mechanical properties}

F. Sánchez-Correa, C. Vidaurre-Agut, Á. Serrano-Aroca, A. J. Campillo-Fernández*

F. Sánchez-Correa, A.J. Campillo-Fernández

Centre for Biomaterials and Tissue Engineering, CBIT, Universitat Politècnica de València, 46022 Valencia, Spain.

Tel: +34 963877000 ext. 88935; E-mail: alcamfer@ter.upv.es

C. Vidaurre-Agut

Instituto de Tecnología Química, Universitat Politècnica de València, 46022 Valencia, Spain.

\section{Á. Serrano-Aroca}

Bioengineering and Cellular Therapy Group, Department of Applied and Technological Sciences, Faculty of Veterinary and Experimental Sciences, Universidad Católica de Valencia San Vicente Mártir, C/Guillem de Castro 94, 46001, Valencia, Spain. 


\section{Abstract}

A series of hybrid hydrogels of poly(2-hydroxyethyl acrylate), PHEA, and graphene oxide, G-O, with G-O content up to 2 wt $\%$ has been prepared by in situ polymerization. Because PHEA has been used as biomaterial in various applications, has a side chain with the hydroxyl functional group and its mechanical properties are poor, it is a good candidate for reinforcement with G-O. FT-IR, AFM, DSC, the thermal, mechanical and water sorption properties of neat PHEA and PHEA/G-O composites have been studied in order to elucidate the dispersion and interaction between both components. An increase in the water diffusion coefficient and dramatic changes in its mechanical properties are the most remarkable results. Thus, at a nanofiller load of $2 \mathrm{wt} \%$, the novel materials present an increased diffusion coefficient higher than $380 \%$ and the elastic modulus is enhanced by more than $650 \%$ in dry state and by more than $100 \%$ in swollen state, both compared to neat PHEA. These results have been attributed to the excellent interaction between the matrix, PHEA, and the reinforcement, G-O, and could open the door to new applications in the field of biomaterials with higher structural requisites. 


\section{Introduction}

Synthetic polymeric hydrogels have been proposed for many biomedical applications [1-4] due to their good biocompatibility and water permeation properties. Biocompatibility is mainly due to the great sorption of water due to the presence of hydrophilic molecular groups able to form hydrogen bonds with water, such as: $-\mathrm{OH},-$ $\mathrm{COOH},-\mathrm{CONH},-\mathrm{CONH}_{2},-\mathrm{SO}_{3} \mathrm{H}$, etc., which act as a medium for transport of gases and nutrients and gives similar surface properties to those of the living tissue, minimizing surface energy differences.

Poly (2-hydroxyethyl acrylate), PHEA, is a synthetic hydrogel of the acrylates family whose properties, such as water sorption, mechanical, thermal and surface energy have previously been studied [5-8]. Specifically, PHEA has been used as a matrix in hybrid PHEA-silica systems for aspirin release [9], as a component of interpenetrated networks for cartilage implants [10], as a component of nanoparticles [11], microcapsules [12], micelles for controlled release [13], as component of water-soluble copolymers with thermoresponse [14], as polymeric nanogel vector for cellular gene and antisense delivery [15], as substrates for differentiation of postnatal neural stem cells [16], and as hybrid scaffolds for mimicking natural dentin [17]. However, in general, the main disadvantage of hydrogels is their poor mechanical properties, which limits their field of application.

Graphene oxide, G-O, is obtained from chemical oxidation of graphite, increasing the interlaminar distance between platelets, and subsequent mechanical stirring or ultrasound. Thus, oxidized graphite flakes are separated, giving rise to graphene oxide. G-O is amphiphilic, since its basal plane is hydrophobic whereas there are hydrophilic groups at its periphery. In the oxidation process epoxy groups and hydroxyls are 
generated anchored to the basal plane and carbonyl and carboxyl groups are anchored at the edges of the laminae $[18,19]$. G-O is therefore easily dispersible in water and in a large number of organic solvents [20].

Regarding biocompatibility, it can be said that in vitro exposure to graphenes from mammalian cells and bacteria causes a decrease in cell viability due to physical damage to the membrane [21-23]. However, the intrinsic properties of G-O affect cellular responses and its behavior in a real biological environment is still poorly understood.

When graphenes are incorporated into a polymeric matrix their potential toxicity is reduced in mammalian cells [25-28]. Furthermore, it has been reported that bacterial proliferation decreases at the composite surface [24-26], this being an important issue because infection is frequent in biomaterial implantation procedures [27].

The presence of the oxygen groups in G-O improves the interaction with polymer matrices, and a good number of nanocomposites have been described in the scientific literature. The key aspects for a good interaction between matrix and reinforcement are that good interactions be established between both components and an adequate dispersion of the reinforcement in the matrix [28-38]. The manufacturing methods of hybrid materials can be divided into methods without covalent bonds: solution mixing, and melt mixing, as well as in situ polymerization and manufacturing methods of hybrids with covalent bonds between the matrix and the reinforcement.

In solution mixing, G-O or functionalized G-O is incorporated into the polymer matrix by the use of a solvent compatible with both and its subsequent removal by evaporation [39-45]. In melt mixing, the polymer matrix is brought to a low viscosity state and the G-O is mixed therewith through mechanical processes such as extrusion, pressing, etc.[46-49]. In in situ polymerization, the G-O is mixed with monomer units to form a 
solution. The polymerization reaction takes place in the presence of G-O to form a hybrid [50-57].

A different approach used for the incorporation of G-O into the polymer matrix is the chemical modification of G-O with functional groups and subsequent polymerization, in which covalent bonds are established [54,58-61].

Due to the presence of the -OH groups in its side chain, PHEA is a good candidate for reinforcement with graphene oxide, since it can establish multiple hydrogen bonds between the side groups of PHEA and the functional groups of G-O anchored to their basal plane (-COOH, -OH). Several graphene-based hydrogels have been described in the literature for different applications such as adsorbent for water purification [62], temperature-sensitive hydrogels [63], enhanced antimicrobial properties [64], electrode material, tissue engineering, aerogels, transdermal systems for controlled delivery of vitamin C and biosensors [65-68].

Thus, the aim of this work is to obtain mechanically-enhanced PHEA hydrogels which could be used as potential candidates for biomedical applications, e.g. in tissue engineering constructs. 


\section{Experimental Section}

\subsection{Nanocomposite-Hydrogel Preparation}

2-hydroxyethyl acrylate, HEA, (Sigma-Aldrich 96\% pure, stabilized with 200-600 ppm of monomethyl ether hydroquinone), ethyleneglycol dimethacrylate, EGDMA, (Sigma-Aldrich $98 \%$ pure, stabilized with 100 ppm of monomethyl ether hydroquinone), graphene oxide powder, G-O, (Graphenea) and benzoin (Scharlau 98\% pure) were used as received.

HEA with $1 \mathrm{wt} \%$ of EGDMA as crosslinker, $1 \mathrm{wt} \%$ of benzoin as photoinitiator and different G-O contents as nanofiller were polymerized at room temperature under ultraviolet light for $24 \mathrm{~h}$. The polymerization took place in a two-glass mold with a polytetrafluoroethylene spacer to prepare polymer sheets $\sim 0.9 \mathrm{~mm}$ thick. Thus, a series of samples were prepared with HEA/G-O weight ratios 100/0, 99.5/0.5, 99/1 and 98/2 (which will hereafter be called: PHEA, PHEA/0.5\%G-O, PHEA/1\%G-O and PHEA/2\%G-O, respectively). All the mixtures were sonicated for 20 minutes before polymerization to improve the dispersion of G-O platelets in the monomer solution. After polymerization, the samples were washed in ethanol at room temperature for $72 \mathrm{~h}$, changing the alcohol three times in order to remove low molecular substances. Finally, the samples were dried at $40^{\circ} \mathrm{C}$ in a vacuum to constant weight.

\subsection{Visual examination and Field Emission-SEM}

The morphologies of the hybrids were detected using a Zeiss Ultra 55 Field Emission Scanning Electron Microscopy, (Zeiss Oxford Instruments, Abingdon, United Kingdom). The acceleration voltage was $2 \mathrm{kV}$ and the working distance (WD) was set to $5 \mathrm{~mm}$. 
The samples surface was milled with $\mathrm{Ga}^{+}$ions in order to visualize the G-O flakes distribution inside the samples.

\subsection{AFM}

AFM was performed with a Bruker MultiMode 8 SPM operating in tapping mode in air and with the NanoScope V Controller and NanoScope 8.15 software version. An antimony (n) doped silicon cantilever from Bruker was used with a nominal force constant of $3 \mathrm{~N} / \mathrm{m}$ and resonance frequency of $75 \mathrm{kHz}$. The phase signal was set to zero at the resonance frequency of the tip. The tapping frequency was 5-10\% lower than the resonance frequency. The drive amplitude and amplitude setpoint were $270 \mathrm{mV}$ and 600 $\mathrm{mV}$, respectively, and the ratio between the amplitude setpoint and the free amplitude was 0.83 .

\subsection{FT-IR Analysis}

The spectra shown in this work were taken with a Bruker Tensor 27 FT-IR spectrometer in the wavenumber region between 400 and $4000 \mathrm{~cm}^{-1}$ at room temperature. All measurements were performed by attenuated total reflectance spectroscopy (ATR) with the Smart Multi-Bounce HATR accessory for solids with a $\mathrm{KBr}$ crystal. The spectra shown in this work were the result of 64 scans at the speed of 1 scan per second.

\subsection{Liquid Water Sorption and Diffusion}

Equilibrium liquid water uptakes, h, defined as g water/g dry sample, were determined by weighing the samples in dry state at $60^{\circ} \mathrm{C}$ for 48 hours in vacuum and after immersion in liquid water in equilibrium at $24 \pm 1{ }^{\circ} \mathrm{C}$. Dynamic liquid sorption experiments were conducted immersing the dry samples in water at $24 \pm 1{ }^{\circ} \mathrm{C}$ and 
measuring their weight at selected immersion times. The equilibrium water uptake experiment was conducted in triplicate. If the liquid sorption process is assumed to obey Fick's law, the constant diffusion coefficient D can be calculated with the slope of the plot $\frac{(\Delta \mathrm{m})_{\mathrm{t}}}{(\Delta \mathrm{m})_{\infty}}$ vs. $\frac{\sqrt{\mathrm{t}}}{\mathrm{l}}[69]$

\subsection{Differential Scanning Calorimetry}

Samples for DSC were cut from the plates and subsequently pressed into the DSC pans. DSC was performed in a PerkinElmer 8000. Helium gas was passed through the DSC cell with a flow rate of $20 \mathrm{ml} / \mathrm{min}$. The temperature of the equipment was calibrated with water and indium. The melting heat of indium was used for calibrating the heat flow. The samples were subjected to a heating scan from ambient temperature to $50^{\circ} \mathrm{C}$, followed by a cooling scan from $50^{\circ} \mathrm{C}$ to $-70{ }^{\circ} \mathrm{C}$ and, finally, a heating scan from that temperature to $50{ }^{\circ} \mathrm{C}$ - both scans at a rate of $20^{\circ} \mathrm{C} / \mathrm{min}$. The characteristic transition temperatures were calculated from the DSC thermograms. The temperature of the extrapolated half $\mathrm{Cp}$ of the thermogram was taken as the glass transition temperature, Tg, of the samples. The thermograms observed were obtained from three replicates.

\subsection{Thermogravimetric Analysis}

Thermogravimetric analyses (TGA) of the samples were carried out in a TGA/DSC 2 STAR System (Mettler Toledo) thermobalance, at $10{ }^{\circ} \mathrm{C} \cdot \mathrm{min}^{-1}$ from 30 to $800{ }^{\circ} \mathrm{C}$ in a nitrogen atmosphere of $50 \mathrm{~mL} \cdot \mathrm{min}^{-1}$ to determine the actual inorganic contents and determine the thermodecomposition profiles. Samples of $\sim 4 \mathrm{mg}$ were analyzed each time. The thermograms observed were obtained from three replicates. 


\subsection{Stress-strain Assay}

The mechanical properties of poly(2-hydroxyethyl acrylate)/graphene oxide samples were measured on a universal tensile testing machine (Microtest, Deben UK Ltd.) at 20 ${ }^{\circ} \mathrm{C}$ in dry and swollen states. The distance between clamps was $10 \mathrm{~mm}$ and the sample dimensions were $30 \mathrm{~mm}$ in length, $5 \mathrm{~mm}$ in width and $0.9 \mathrm{~mm}$ in thickness. The extension rate was $0.2 \mathrm{~mm} / \mathrm{min}$ and the load cell was $150 \mathrm{~N}$. The experiment was performed in three replicates.

\subsection{Dynamic Mechanical Spectroscopy}

Rectangular samples $\left(20 \times 9.25 \times 0.9 \mathrm{~mm}^{3}\right)$ were cut from the plates for dynamicmechanical analysis in a DMA 800 (Perkin Elmer) at $1 \mathrm{~Hz}$. The temperature dependence of storage modulus $\left(E^{\prime}\right)$, loss modulus $\left(E^{\prime \prime}\right)$ and loss tangent $(\tan \delta)$ was measured from -50 to $80{ }^{\circ} \mathrm{C}$ at a heating rate of $2 \mathrm{~K} \cdot \mathrm{min}^{-1}$. 


\section{Results and Discussion}

\subsection{Visual examination and Field Emision-SEM}

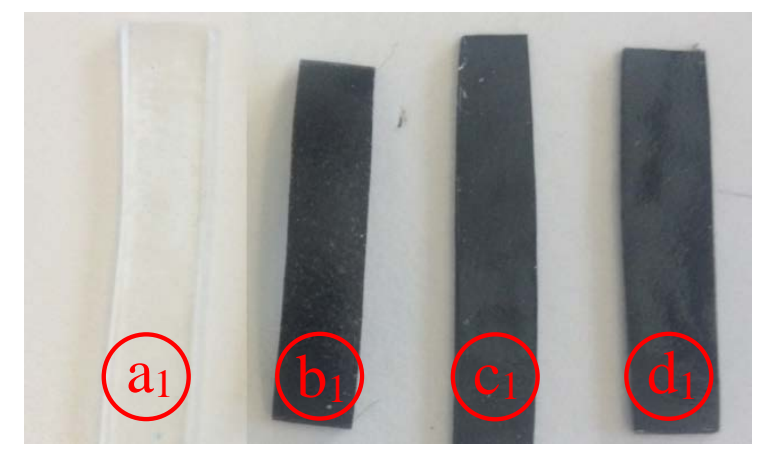

Figure 1. Photographs of samples with different GO content; $\left(\mathrm{a}_{1}\right)$ neat PHEA, $\left(\mathrm{b}_{1}\right)$ PHEA/0.5\%G-O, ( $\left.\mathrm{c}_{1}\right)$ PHEA/1\%G-O; $\left(d_{1}\right)$ PHEA/2\%G-O.

As can be seen in Fig. 1 the series of samples shows intense blackening with the G-O content. Furthermore, there were no significant differences in color between PHEA/0.5\%G-O, PHEA/1\%G-O and PHEA/2\%G-O.
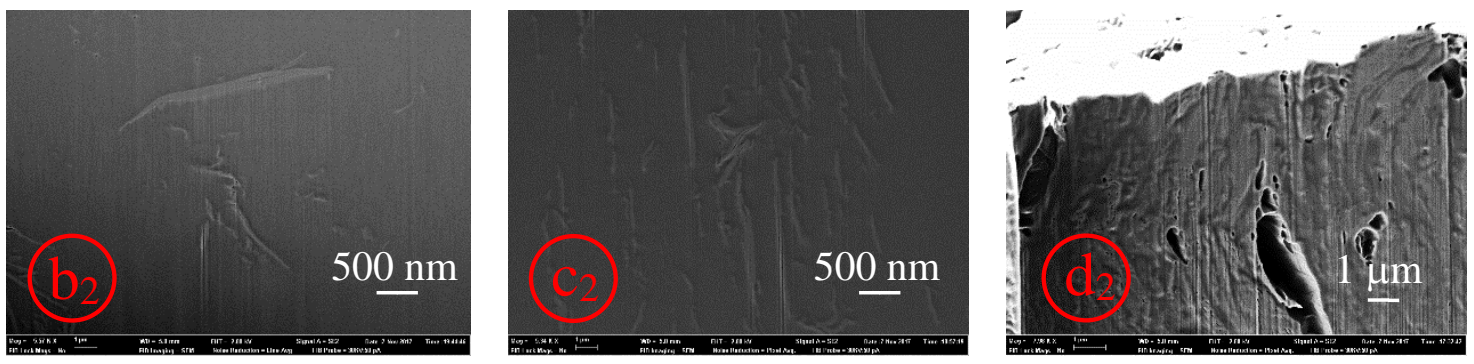

Figure 2. FESEM images of the samples inside with different G-O content; (b2) PHEA/0.5\%G-O, (c2) PHEA/1\%G-O; $\left(\mathrm{d}_{2}\right)$ PHEA/2\%G-O.

Fig.2 shows the FESEM images of the samples inside. As expected, an increase of GO flakes with the G-O content as well as an intimate union between the matrix and the reinforcement can be observed. 


\subsection{AFM}

Figure 3 shows the AFM images of the different G-O content composites over a scan area of $5 \mu \mathrm{m} \times 5 \mu \mathrm{m}$. The pictures of the topography and phase angle clearly indicate that the surface of the PHEA is completely homogeneous. However, different viscoelastic properties are clearly revealed in the composites. In order to obtain the surface roughness parameters as a function of G-O content an area of $30 \mu \mathrm{m} \times 30 \mu \mathrm{m}$ was scanned for each sample. The results are shown in Table 1 . The mean roughness $\left(R_{a}\right)$ and the root mean square of the $\mathrm{Z}$ data $\left(\mathrm{R}_{\mathrm{q}}\right)$ were found to increase monotonously with $\mathrm{G}-\mathrm{O}$ content. These results suggest that that G-O flakes induce a distortion in the macromolecular structure.
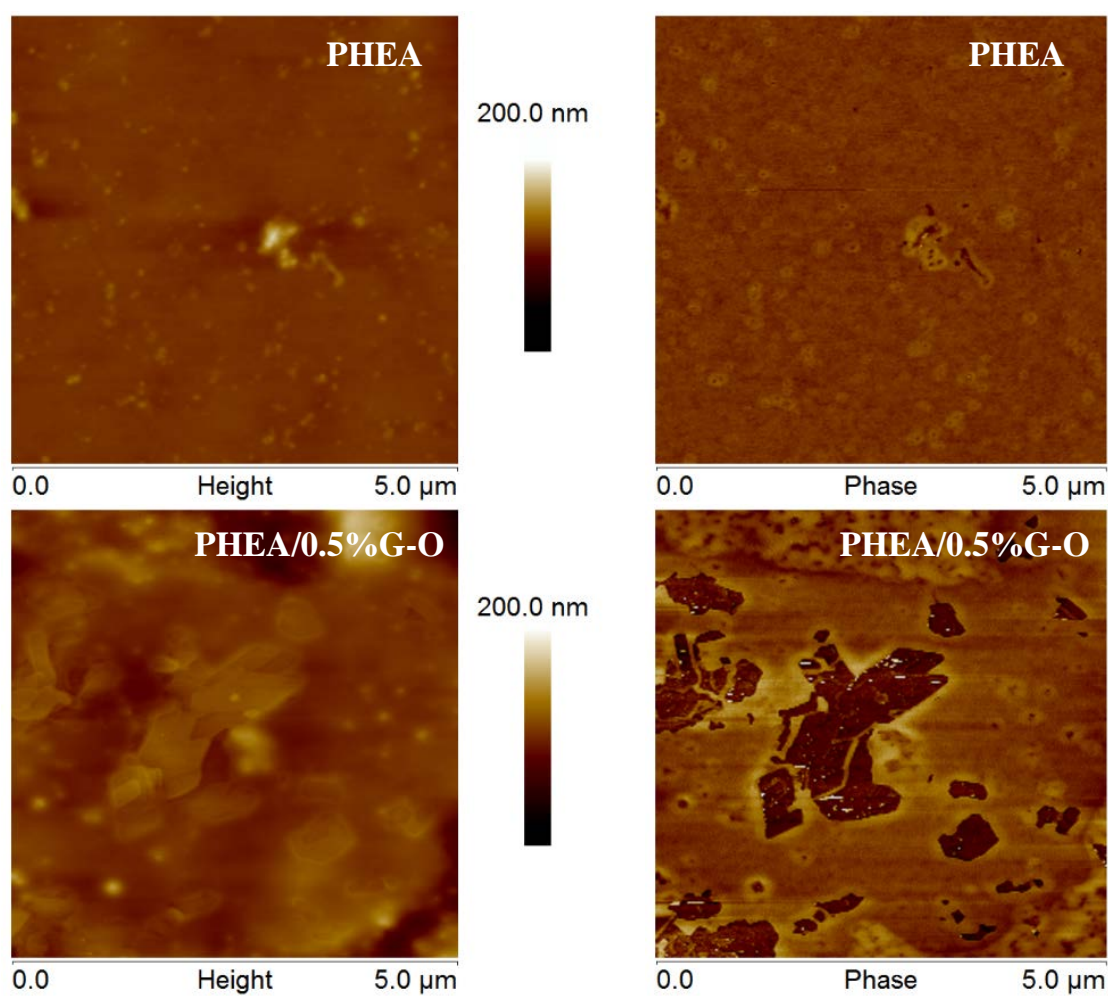

$60.0^{\circ}$

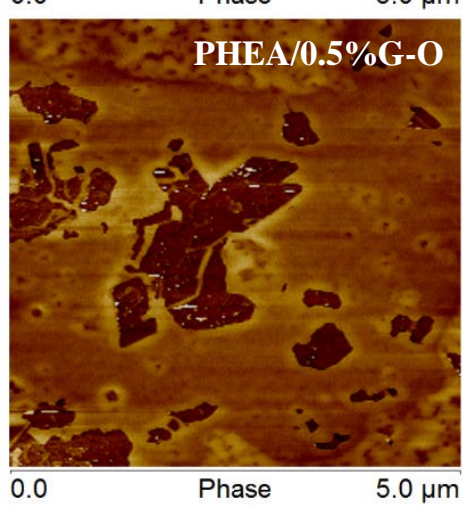

$60.0^{\circ}$

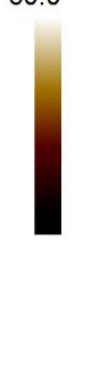



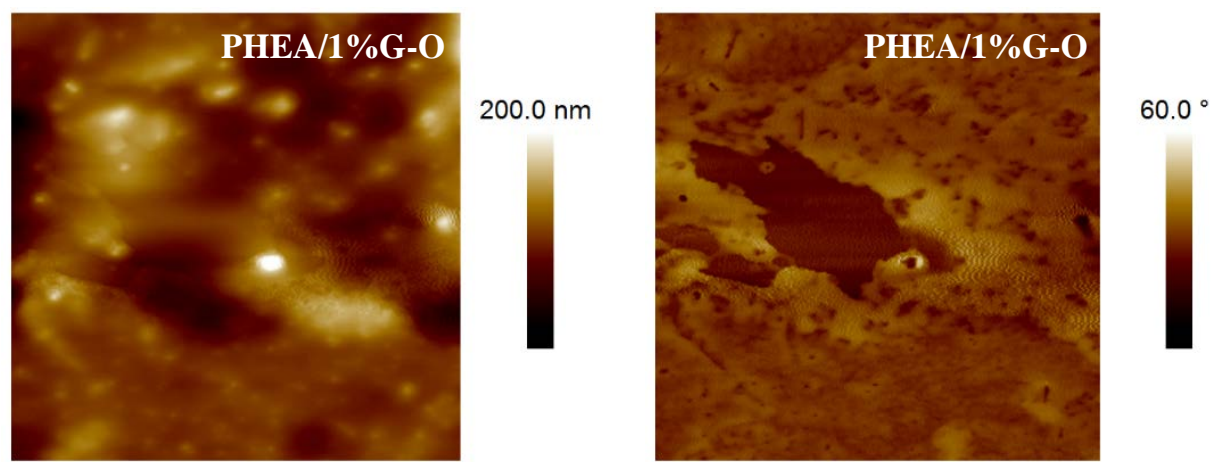

0.0

Height

$5.0 \mu \mathrm{m}$

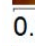

0.0

Phase

$5.0 \mu \mathrm{m}$

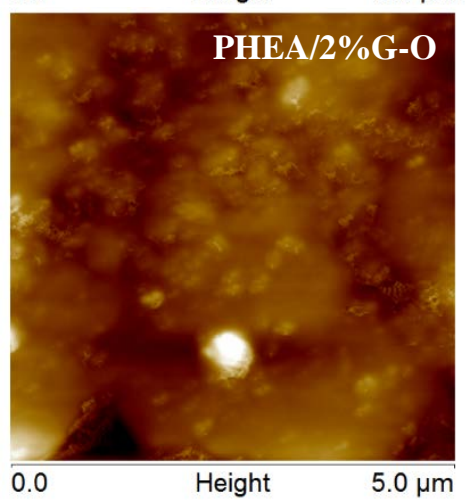

$200.0 \mathrm{~nm}$

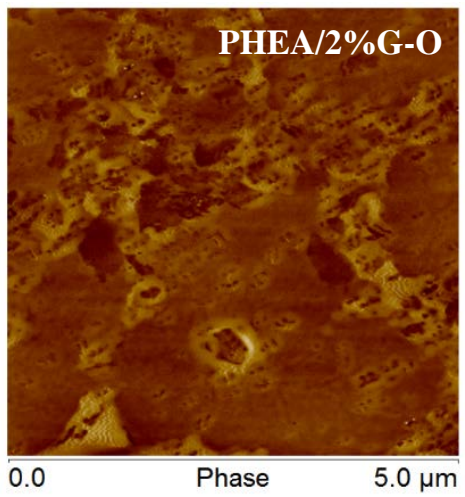

$60.0^{\circ}$

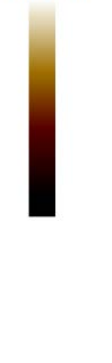

Figure 3. AFM topography images (left) and phase images (right) recorded in tapping mode of the composites with different G-O content scanning a $5 \mu \mathrm{m}$ x $5 \mu \mathrm{m}$ area.

\begin{tabular}{|c|c|c|}
\cline { 2 - 3 } \multicolumn{1}{c|}{} & Image Ra (nm) & Image Rq (nm) \\
\hline PHEA & 9.93 & 29.3 \\
\hline PHEA/0.5\%G-O & 212 & 285 \\
\hline PHEA/1\%G-O & 236 & 342 \\
\hline PHEA/2\%G-O & 634 & 795 \\
\hline
\end{tabular}

Table 1. Mean roughness $\left(R_{a}\right)$ and the root mean square of the $Z$ data $\left(R_{q}\right)$ for PHEA/G-O composites over a scan surface of $30 \mu \mathrm{m} \times 30 \mu \mathrm{m}$. 


\subsection{FT-IR}

FT-IR spectra of G-O and G-O composites are shown in Fig. 4. Characteristic peaks are $\mathrm{C}=\mathrm{O}$ stretching mode at $1719 \mathrm{~cm}^{-1}, \mathrm{O}-\mathrm{H}$ bending mode at $1412 \mathrm{~cm}^{-1}, \mathrm{C}-\mathrm{OH}$ stretching mode at $1226 \mathrm{~cm}^{-1}$ and the $\mathrm{C}-\mathrm{O}$ stretching mode at $1053 \mathrm{~cm}^{-1}$. [70-72] The presence of $\mathrm{O}-\mathrm{H}$ stretching mode appears as a broad peak between 3000 and $3600 \mathrm{~cm}^{-1}$ (data not shown). The spectrum of G-O also shows a band at $1621 \mathrm{~cm}^{-1}$, attributed to aromatic carbon double bonds [73] and the $\mathrm{C}-\mathrm{O}$ vibrations of the epoxy groups at around $1139 \mathrm{~cm}^{-1}$ and $873 \mathrm{~cm}^{-1}$. [74,75] The FT-IR results show no significant change between PHEA and PHEA nanohybrids spectra.

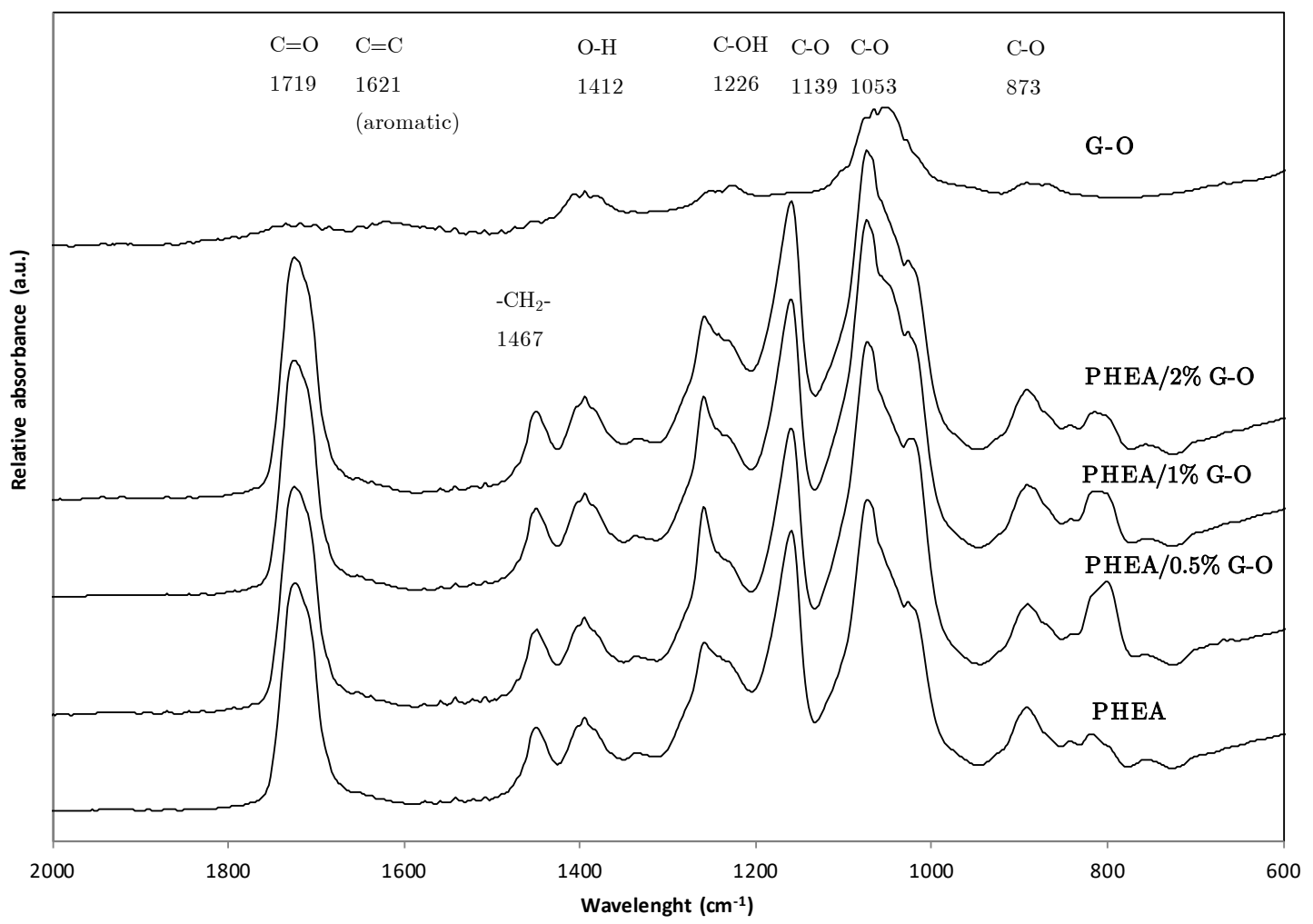

Figure 4. FT-IR spectra for G-O and nanohybrids with different G-O contents. 


\subsection{Water Interaction. Liquid Water Sorption and Diffusion}

Figure 5 shows the liquid water uptake for neat PHEA and hybrids. As can be seen, the slope of the plot increases as the G-O content increases monotonously. Results of diffusion coefficients and water uptake are summarized in Table 2. As the G-O content increases, the water absorption capacity of the samples decreases, probably due to the inaccessibility of water to interact with the hydroxyls of PHEA (partially interacting with the G-O), but mainly because PHEA chains have a reduced mobility constricted by the G-O plates, which reduces the reorganization of the macromolecules, thus reducing the hydroxyl groups exposed to water. Because the network is constrained by the graphene plates, it cannot expand to accommodate higher water content and its water uptake is smaller.

However, the speed at which the water molecules interact with the hybrids increases substantially with graphene content, from $2.24 \cdot 10^{-7} \mathrm{~s}^{0.5} \cdot \mathrm{cm}^{-1}$ for the neat PHEA to $8.67 \cdot 10^{-7} \mathrm{~s}^{0.5} \cdot \mathrm{cm}^{-1}$ for PHEA/2\%G-O, which represents a remarkable increase of more than $380 \%$. The increase of diffusion coefficient can be explained because the incoming water molecules interact with the hydroxyls of PHEA and this takes a while, i.e., the reverse dependence of $\mathrm{D}$ on the hydrophilicity of the sample can be explained by the additional time needed to rupture and restore the hydrogen bonds during the motion of the water molecules along their diffusion paths[76].

These results are indicative that there is a strong interaction between PHEA and G-O. 


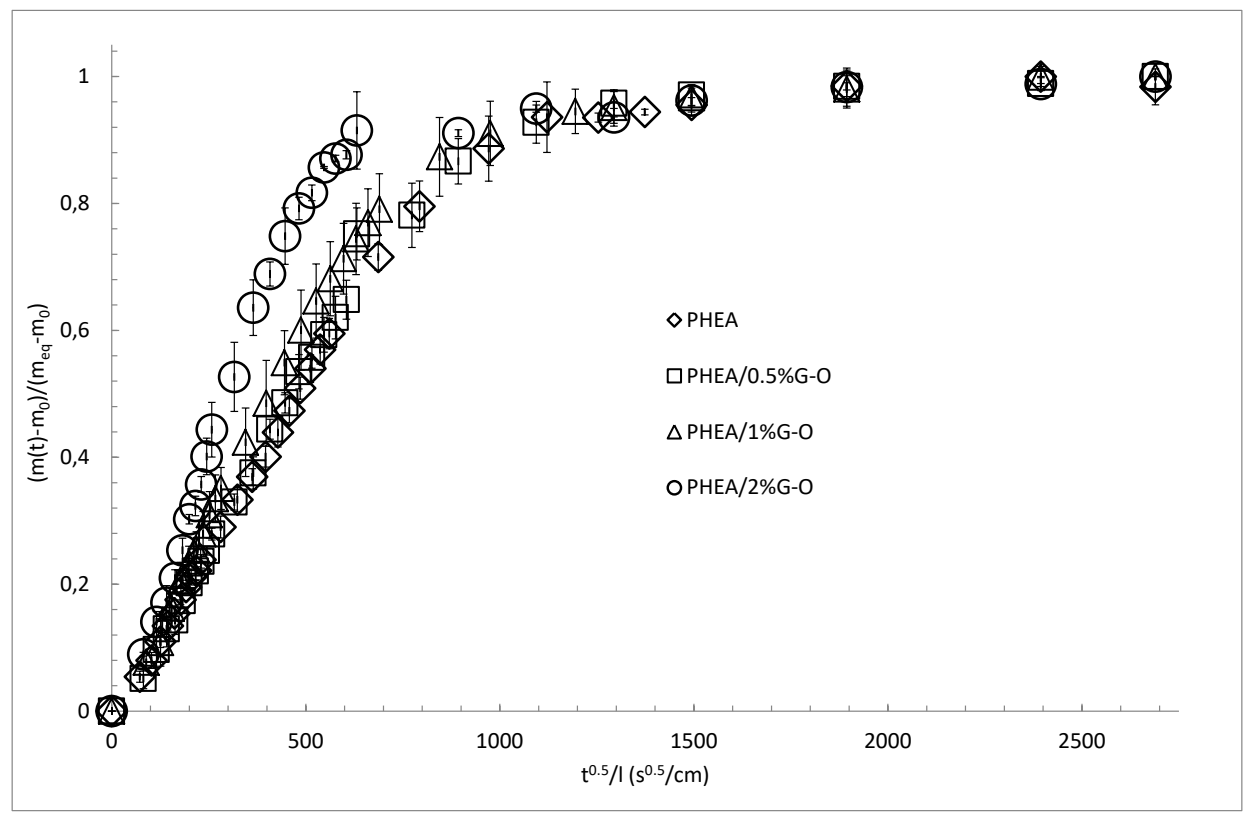

Figure 5. Water uptake for neat PHEA and PHEA/G-O hybrids as a function of time.

\begin{tabular}{|c|c|c|}
\cline { 2 - 3 } \multicolumn{1}{c|}{} & $\begin{array}{c}\text { Diffusion coefficient }\left(\mathbf{x 1 0}^{\mathbf{7}}\right) \\
\left(\mathbf{s}^{\mathbf{0 . 5}} \cdot \mathbf{c m}^{\mathbf{- 1}}\right)\end{array}$ & $\begin{array}{c}\text { Water Uptake } \\
\mathbf{( \% )}\end{array}$ \\
\hline PHEA & $2.24 \pm 0.24$ & $208 \pm 10$ \\
\hline PHEA/0.5\%G-O & $2.69 \pm 0.54$ & $160 \pm 9$ \\
\hline PHEA/1\%G-O & $4.25 \pm 0.86$ & $125 \pm 11$ \\
\hline PHEA/2\%G-O & $8.67 \pm 0.82$ & $95 \pm 4$ \\
\hline
\end{tabular}

Table 2. Diffusion coefficients and water uptakes for neat PHEA and PHEA/G-O hybrids. 


\subsection{Thermal Characterization}

\subsubsection{DSC}

The DSC traces of pure PHEA and PHEA/G-O nanocomposites are shown in Figure 6. Pure PHEA shows a glass transition temperature at $3.17 \pm 2.25{ }^{\circ} \mathrm{C}$. All of the nanocomposites showed higher Tg values than neat PHEA. Figure 7 shows Tg mean values and standard deviation vs. G-O content of the nanohybrids shown in Table 3.

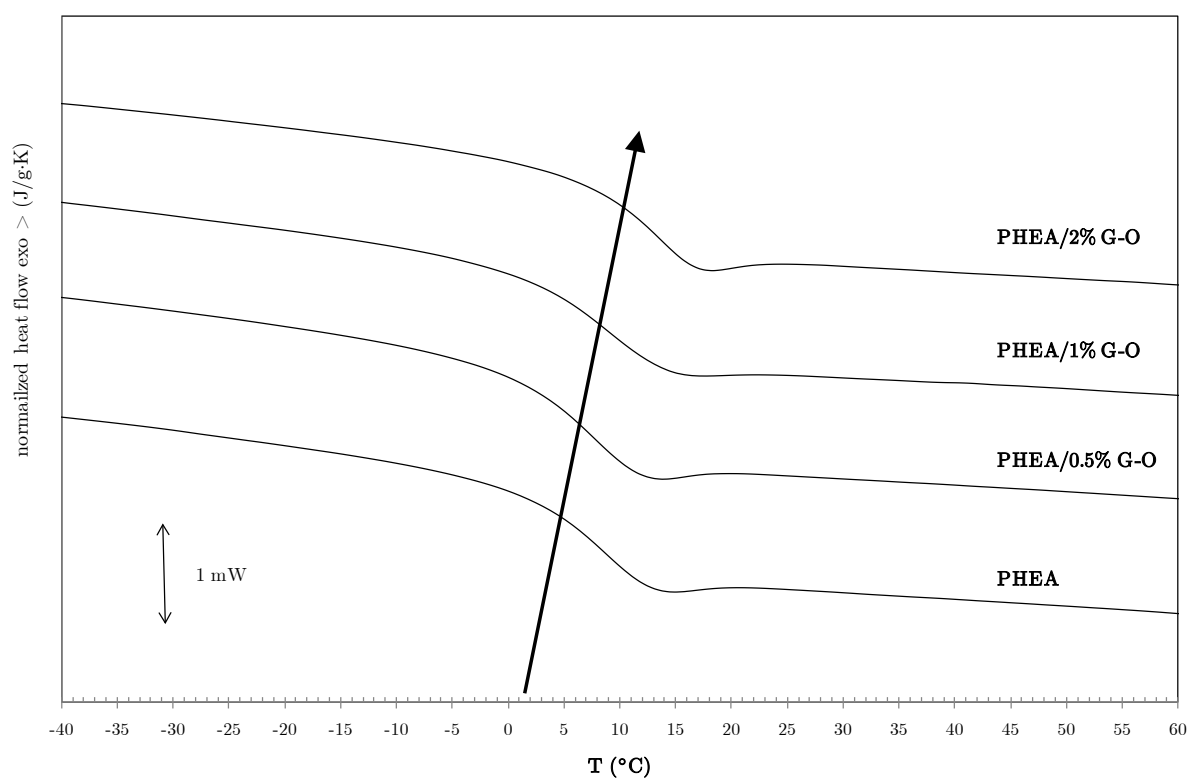

Figure 6. DSC traces of PHEA and PHEA/G-O composites.

\begin{tabular}{|c|c|}
\cline { 2 - 2 } \multicolumn{1}{c|}{} & $\operatorname{Tg}\left({ }^{\circ} \mathbf{C}\right)$ \\
\hline PHEA & $3.17 \pm 2.25$ \\
\hline PHEA/0.5\% G-O & $5.33 \pm 1.53$ \\
\hline PHEA/1\% G-O & $5.33 \pm 1.53$ \\
\hline PHEA/2\% G-O & $8.00 \pm 2.18$ \\
\hline
\end{tabular}

Table 3. Glass transition temperatures mean values and standard deviations of PHEA and hybrids as a function of G-O content. 


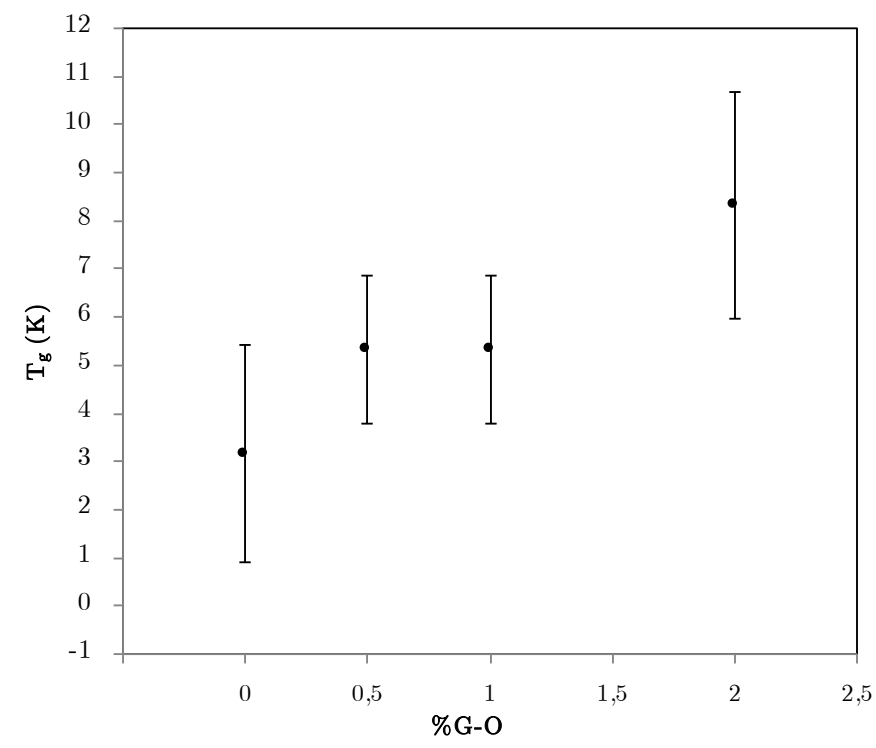

Figure 7. Glass transition temperature as a function of G-O content.

It can be observed that Tg increases with G-O content, and it is attributed to the difficulty imposed by the G-O sheets on conformational movements of the polymeric macromolecules. Interestingly, the results seem to indicate a pronounced increase in Tg with low G-O contents, which indicates that the distortion of the network occurs with inclusion of the first G-O flakes.

In figure 8, Cp increments per PHEA gram has been represented as a function of G-O in order to elucidate if the addition of G-O induces a modification in the mass of polymer that contributes to glass transition. Dot line represents $\Delta \mathrm{Cp}$ for neat PHEA and as it is shown mean values for the hybrids are over the neat PHEA one, what indicates that part of the polymer matrix of neat PHEA does not contribute to glass transition (e.g. nanocrystals formation); the addition of G-O flakes destroys the immobilized zones, so a higher polymer mass is disposable to contribute the transition. 


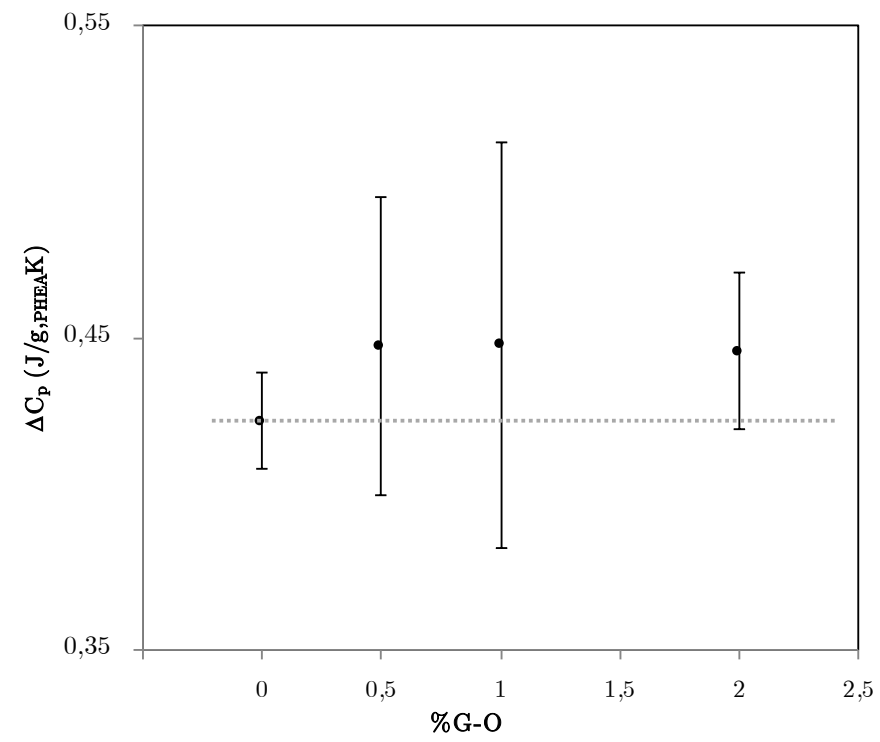

Figure 8. Glass transition temperature as a function of G-O content.

\subsubsection{TGA}

The thermogravimetric (TG) and derivative thermogravimetric (DTG) curves of PHEA and PHEA/G-O nanocomposites are shown in Figures 9 and 10, respectively.

For G-O, three stages are distinguished: the first between room temperature and 130 ${ }^{\circ} \mathrm{C}$ with a mass loss of around $20 \%$, which can be attributed to the removal of adsorbed water; a second one between $130{ }^{\circ} \mathrm{C}$ and $210{ }^{\circ} \mathrm{C}$ with a mass loss of around $20 \%$ can be attributed to the removal of labile oxygen functionalities; finally, more stable oxygen functionalities are removed above $300{ }^{\circ} \mathrm{C}$.

Table 4 shows the initial decomposition temperature, IDT (the temperature of $5 \mathrm{wt} \%$ weight loss), the $\mathrm{T}_{\max }$ (temperature of maximum rate degradation), the residue at $800^{\circ} \mathrm{C}$ and the theoretical residue that the samples would have had if their behavior had been an ideal mixture. That is the criteria to be used to understand if there are interactions between both components. In order to calculate the theoretical residue of each sample the Equation (1) has been used 


$$
\frac{\Delta m}{m 0}=w_{P H E A} \cdot \frac{\Delta m_{P H E A}}{m_{0, P H E A}}+\left(1-w_{P H E A}\right) \cdot \frac{\Delta m_{G O}}{m_{0, G O}}
$$

As observed, IDT of hybrids decreases with the increases in G-O, which could be related to the loss of labile oxygen G-O groups.

The DTG curves (Figure 7) of neat PHEA and its nanocomposites reveal a two-stage degradation process: the first at around $200{ }^{\circ} \mathrm{C}$ with a mass loss of $\sim 10 \%$, and a second at around $435{ }^{\circ} \mathrm{C}$. The temperatures of the maximum rate of degradation $\left(\mathrm{T}_{\max }\right)$ for PHEA and its G-O nanocomposites remain fairly constant, showing a slight increment with G-O content, probably due to the fact that G-O prevents diffusion of the mass of PHEA.

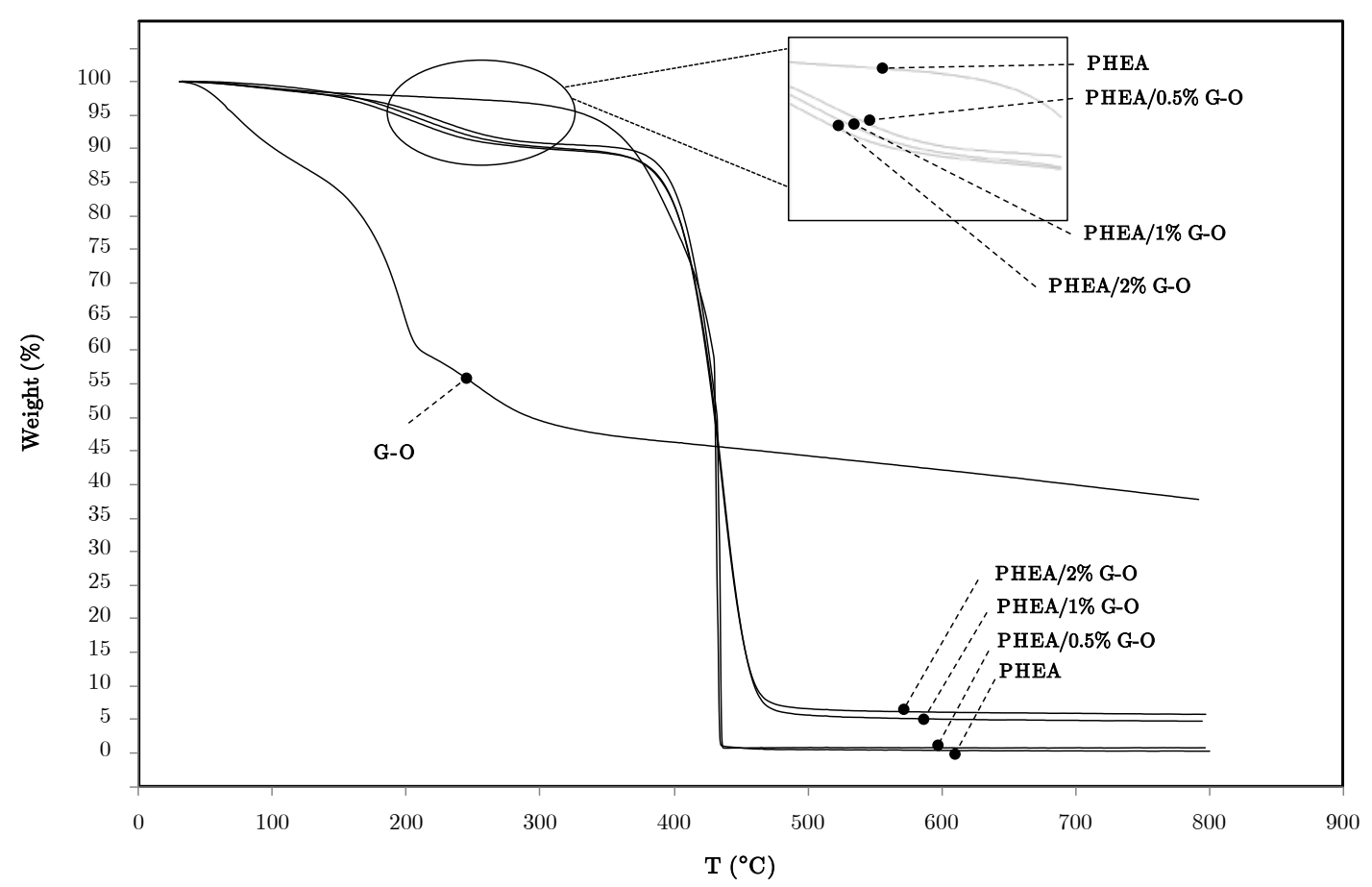

Figure 9. TG plots of PHEA and PHEA/G-O nanocomposites 


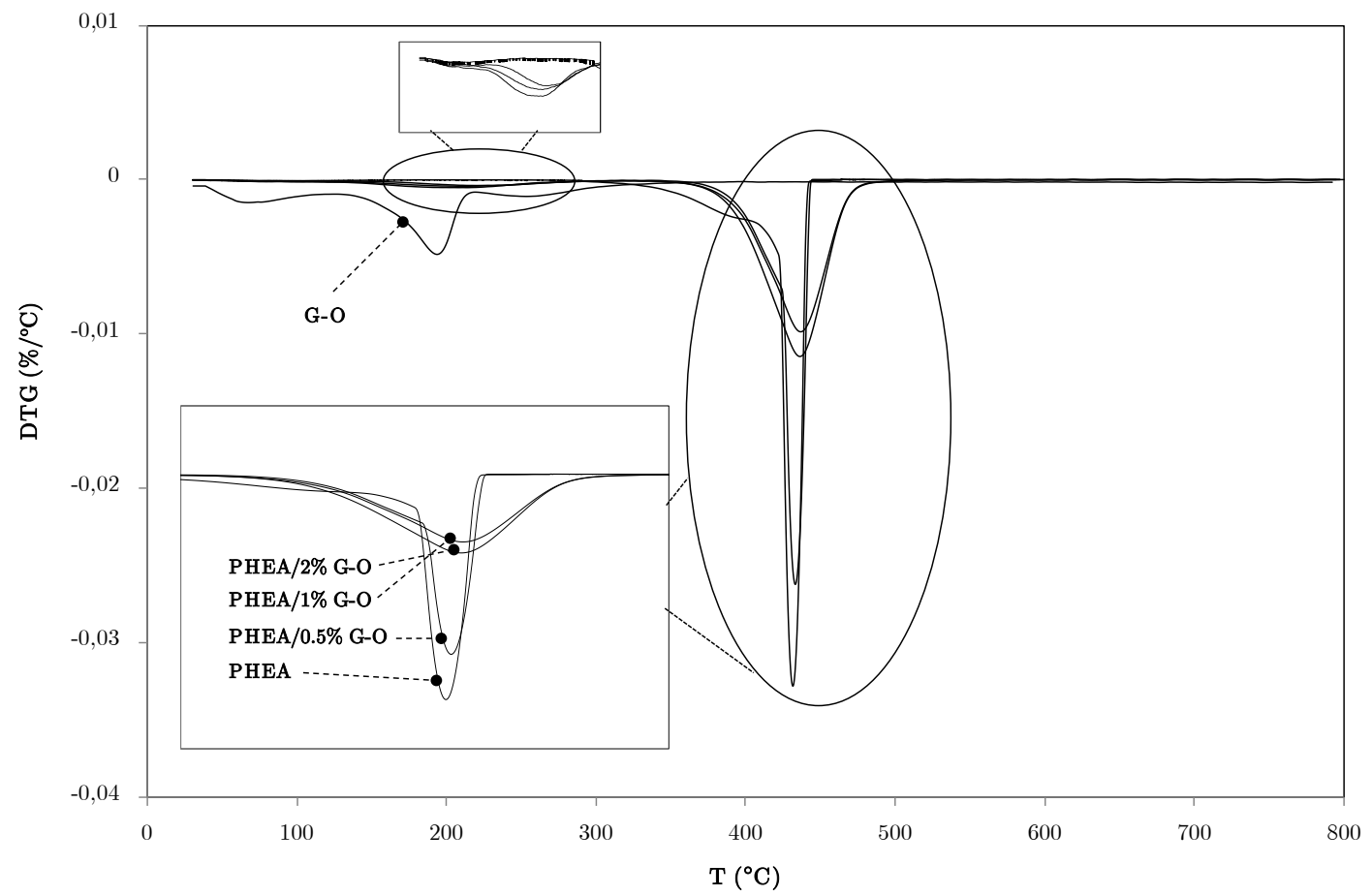

Figure 10. DTG plots of PHEA and PHEA/G-O nanocomposites

\begin{tabular}{|c|c|c|c|c|}
\hline & IDT $\left({ }^{\circ} \mathrm{C}\right)$ & $\mathbf{T}_{\max }\left({ }^{\circ} \mathrm{C}\right)$ & $\begin{array}{c}\text { Residue at } 800^{\circ} \mathrm{C} \\
\text { (\%) }\end{array}$ & $\begin{array}{c}\text { Theoretical Residue at } 800^{\circ} \mathrm{C} \\
\text { (\%) }\end{array}$ \\
\hline G-O & 71.82 & 193.8 & 37.7 & \\
\hline PHEA & 334.61 & 431.52 & 0.28 & \\
\hline PHEA/0.5\%G-O & 213.48 & 433.30 & 0.79 & 0.47 \\
\hline PHEA/1\%G-O & 203.06 & 436.93 & 4.75 & 0.65 \\
\hline PHEA/2\%G-O & 193.51 & 436.36 & 5.76 & 1.02 \\
\hline
\end{tabular}

Table 4. Thermal properties of PHEA and PHEA/G-O nanocomposites

The equation [1] predicts that residues at $800^{\circ} \mathrm{C}$ should be $0.47 \%, 0.65$ and $1.02 \%$ for $0.5 \%$ of $\mathrm{G}-\mathrm{O}, 1 \%$ of G-O and $2 \%$ of G-O, respectively. Nonetheless, the real residues are higher than those predicted by equation [1] being $0.79 \%, 4.75 \%$ and $5.76 \%$ for $0.5 \%$ of G-O, 1\% of G-O and 2\% of G-O. Figure 11 shows the theoretical and real curves for PHEA/G-O 5\%. This result indicates an excellent interaction between both components. 


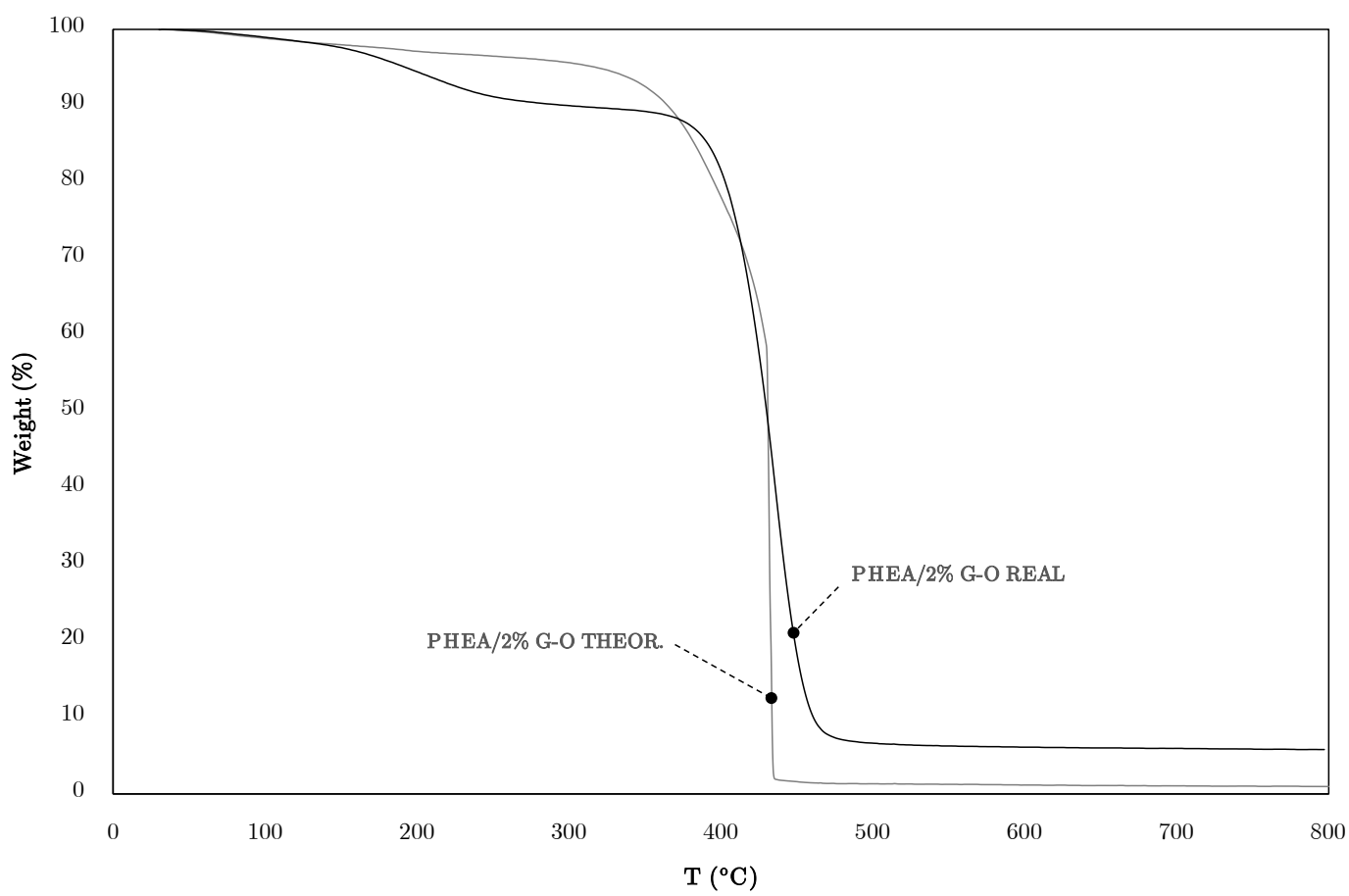

Figure 11. PHEA/2\% G-O thermogravimetric curves. Black line represents real weight loss. Grey line represents the theoretical prediction. 


\subsection{Mechanical Properties}

\subsubsection{Stress-Strain Assay}

Figure 12 shows the tensile stress-strain plot of neat PHEA and the different nanohybrids in dry state. As can be observed, the modulus of the hybrids increases significantly with G-O content. At a nanofiller load of $2 \mathrm{wt} \%$, the hybrid presented an enhancement of the elastic modulus by more than $650 \%$ thus confirming a good interaction between the polymer matrix and G-O. The enhancement of the mechanical properties of the PHEA/G-O nanocomposites in dry state can be ascribed to the dispersion of graphene sheets in the polymer matrix and the strong interfacial interactions between both components.

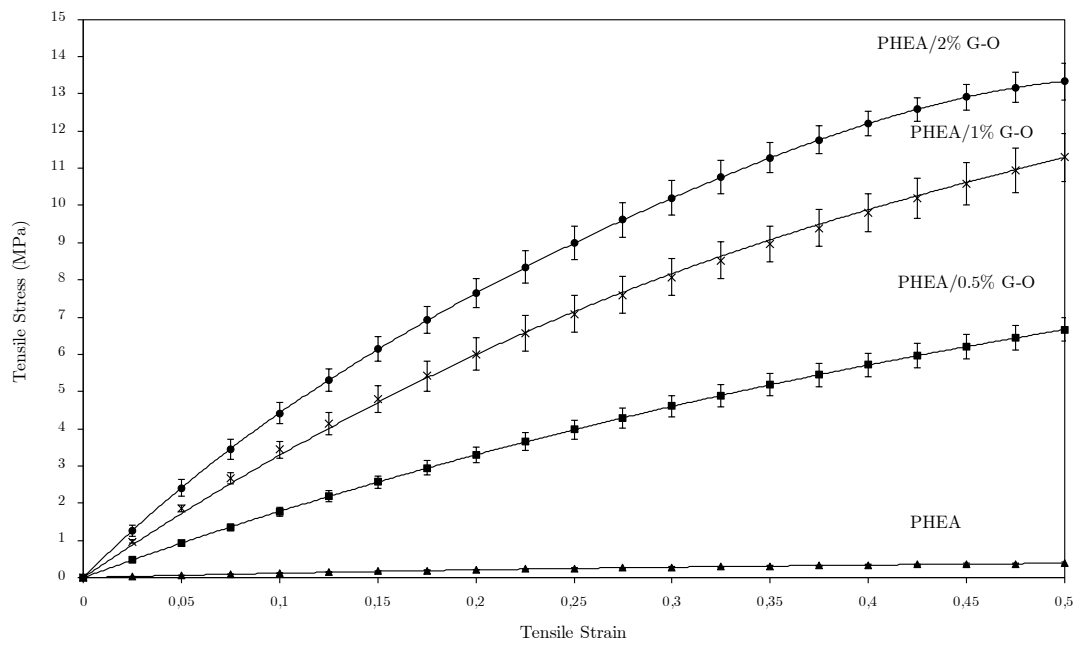

Figure 12. Tensile stress-strain of neat PHEA and PHEA hybrids as a function of G-O content.

Table 5 summarize the modulus and the ultimate tensile stress in dry and swollen state as a function of G-O content. 


\begin{tabular}{|c|c|c|c|c|}
\hline & \multicolumn{2}{|c|}{ Dry state } & \multicolumn{2}{|c|}{ Swollen state } \\
\hline & $\begin{array}{c}\text { Modulus } \\
\text { (MPa) }\end{array}$ & Ultimate Tensile Stress & $\begin{array}{c}\text { Modulus } \\
\text { (MPa) }\end{array}$ & $\begin{array}{c}\text { Ultimate Tensile } \\
\text { Stress }\end{array}$ \\
\hline PHEA & $0.77 \pm 0.05$ & $\begin{array}{l}\text { No break at } 100 \% \\
\text { Tensile Strain }\end{array}$ & $0.57 \pm 0.14$ & $\begin{array}{c}0.077 \mathrm{MPa} \text { at } 14.2 \% \\
\text { Tensile Strain }\end{array}$ \\
\hline PHEA/0.5\%G-O & $13.33 \pm 0.64$ & $\begin{array}{l}\text { No break at } 100 \% \\
\text { Tensile Strain }\end{array}$ & $0.71 \pm 0.06$ & $\begin{array}{c}0.166 \mathrm{MPa} \text { at } 27.1 \% \\
\text { Tensile Strain }\end{array}$ \\
\hline PHEA/1.0\%G-O & $22.60 \pm 1.29$ & $\begin{array}{c}13 \text { Mpa at } 70 \% \text { Tensile } \\
\text { Strain }\end{array}$ & $1.78 \pm 0.10$ & $\begin{array}{c}0.454 \mathrm{MPa} \text { at } 40.3 \% \\
\text { Tensile Strain }\end{array}$ \\
\hline
\end{tabular}

Table 5. Modulus and ultimate tensile stress of net PHEA and PHEA composites.

As expected, when hybrids are immersed in water the mechanical properties decrease. It important to notice that G-O flakes inside the polymer matrix increase the mechanical modulus and the ultimate tensile stress and at a nanofiller load of $2 \mathrm{wt} \%$, the hybrid presented an enhancement of the elastic modulus by more than $100 \%$ in swollen state, what it is a remarkable difference between neat PHEA and the hybrids.

\subsubsection{Viscoelastic Characterization}

Figure 13 shows the viscoelastic behavior of the nanohybrids evaluated by DMTA analysis. It can be observed that the main relaxation of PHEA increases with G-O content, from $17.1{ }^{\circ} \mathrm{C}$ for neat PHEA to $22.3^{\circ} \mathrm{C}$ for PHEA/2\%G-O nanocomposite. The main relaxation (Table 6) shows the same trend as observed in DSC, which indicates that the polymer chains are constrained by the interactions between the polymer matrix and G-O, affecting the mobility of the polymer chains.

Furthermore, in consonance with the stress-strain assay results in dry state, adding GO to PHEA induces an increase of the storage modulus, from $0.488 \mathrm{MPa}$ for neat PHEA to $3.181 \mathrm{MPa}$, which represents an increase of $651.8 \%$. This is a remarkable result, 
since it clearly highlights the considerable increase in mechanical performance achieved by the composites, probably due to the good interaction between the polymeric chains and the graphene platelets, with the consequent increase on stiffness values.

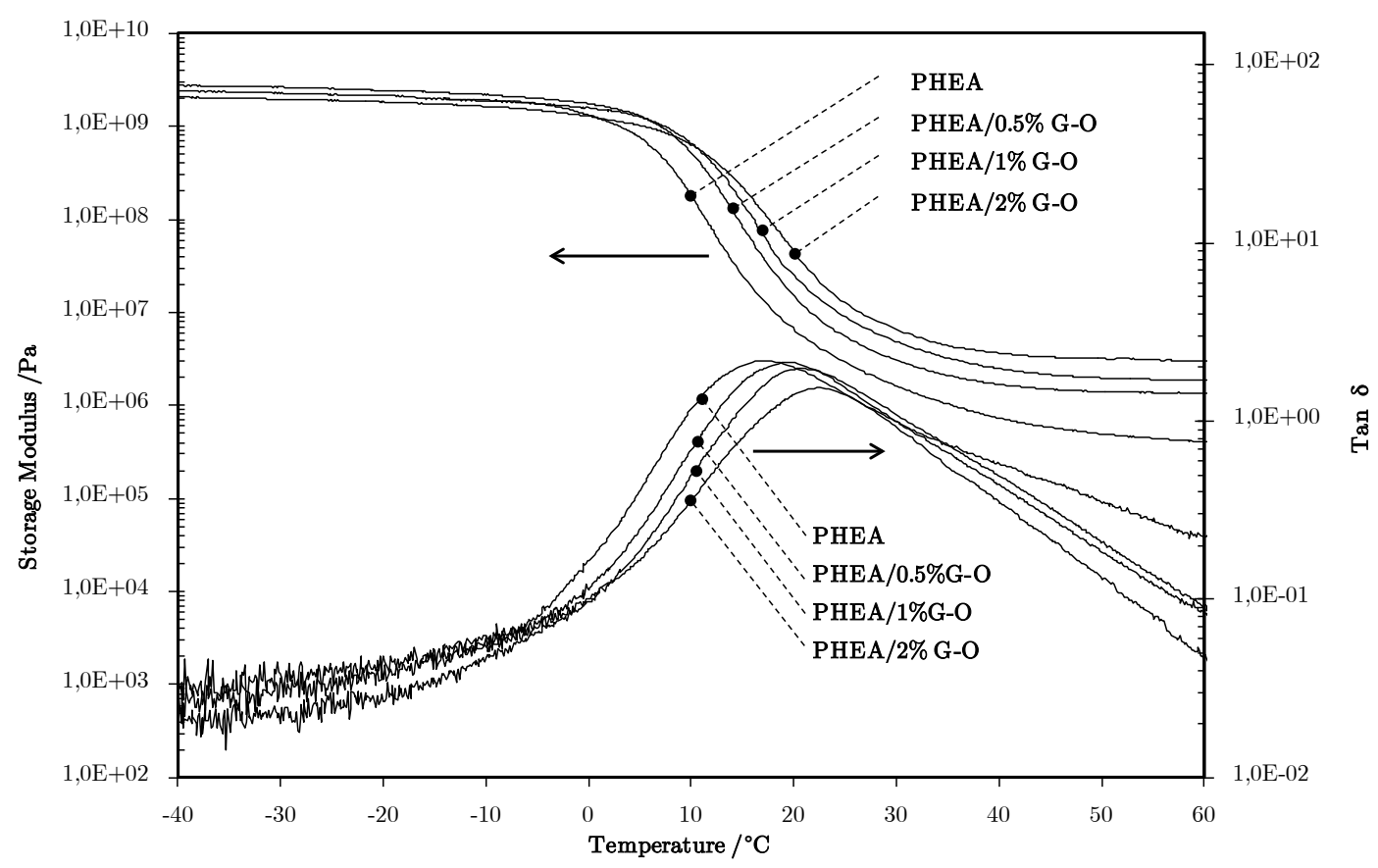

Figure 13. Temperature dependence of the elastic modulus (left) and the loss tangent (right) of the different samples.

\begin{tabular}{|l|c|c|c|}
\cline { 2 - 4 } \multicolumn{1}{c|}{} & $\mathbf{E}^{\prime}{ }_{50}{ }^{\circ} \mathbf{C}$ (MPa) & E' increase (\%) & Tan $\delta$ peak $\left({ }^{\circ} \mathbf{C}\right)$ \\
\hline PHEA & 0.488 & - & 17.1 \\
\hline PHEA-0.5\% G-O & 1.402 & $287,3 \%$ & 19.7 \\
\hline PHEA- 1\% G-O & 1.965 & $402,7 \%$ & 20.8 \\
\hline PHEA - 2\% G-O & 3.181 & $651,8 \%$ & 22.3 \\
\hline
\end{tabular}

Table 6. Elastic modulus at $50^{\circ} \mathrm{C}$, increase in \% of the elastic modulus respect to neat PHEA and temperature of the peak in loss tangent of the different samples.

\section{Conclusions}

A series of hybrid hydrogels of PHEA and G-O with different G-O contents were characterized in order to elucidate the interaction between both components. An increased water diffusion coefficient and the mechanical properties of the novel materials as compared to neat PHEA were the most remarkable results, thus confirming 
the excellent interaction between both components. The interaction constrains the mobility of polymer chains, thus modifying the properties of the hybrids as compared to neat polymer. These results could open the door to new applications in the field of biomaterials with higher structural requisites.

\section{Acknowledgements}

This work was supported by Project GV/2016/067 of the Generalitat Valenciana,

AFM and the stress-strain assay was conducted by the authors in the Microscopy Service of the Universitat Politècnica de València, whose advice is greatly appreciated.

The authors acknowledge Prof. M. Monleón-Pradas for his helpful discussions.

\section{Conflicts of Interest}

The authors declare no conflict of interest.

\section{Keywords}

Composites; hydrogels; diffusion; mechanical properties; thermal properties 

Surg., Springer US, Boston, MA, 1975: pp. 33-44. doi:10.1007/978-1-4684-7744-3_3.

N.A. Peppas, R. Langer, New challenges in biomaterials, 1994. doi:10.1126/science.8134835.

C.L. Bell, N.A. Peppas, Biomedical membranes from hydrogels and interpolymer complexes, in: N.A. Peppas, R.S. Langer (Eds.), Biopolym. II, Springer Berlin Heidelberg, Berlin, Heidelberg, 1995: pp. 125-175. doi:10.1007/3540587888_15.

[4] H. Ozawa, S. Hosaka, T. Kunitomo, H. Tanzawa, Ocular inserts for controlled release of antibiotics, Biomaterials. 4 (1983) 170-174. doi:10.1016/0142-9612(83)90005-4.

[5] M.M. Pradas, J.L.G. Ribelles, A.S. Aroca, G.G. Ferrer, J.S. Antón, P. Pissis, Interaction between water and polymer chains in poly(hydroxyethyl acrylate) hydrogels, Colloid Polym. Sci. 279 (2001) 323-330. doi:10.1007/s003960000426.

[6] A.J. Campillo-Fernandez, S. Pastor, M. Abad-Collado, L. Bataille, J.L. Gomez-Ribelles, J.M. Meseguer-Dueñas, M. Monleon-Pradas, A. Artola, J.L. Alio, J.M. Ruiz-Moreno, Future Design of a New Keratoprosthesis. Physical and Biological Analysis of Polymeric Substrates for Epithelial Cell Growth, Biomacromolecules. 8 (2007) 2429-2436. doi:10.1021/bm0703012.

M.M. Pradas, J.L.G. Ribelles, A.S. Aroca, G.G. Ferrer, J.S. Anton, P. Pissis, Porous poly(2-hydroxyethyl acrylate) hydrogels, Polymer (Guildf). 42 (2001) 4667-4674.

[8] A. Serrano Aroca, A.J.J. Campillo Fernández, J.L.L. Gómez Ribelles, M. Monleón Pradas, G. Gallego Ferrer, P. Pissis, Porous poly(2-hydroxyethyl acrylate) hydrogels prepared by radical polymerisation with methanol as diluent, Polymer (Guildf). 45 (2004) 8949-8955. doi:10.1016/j.polymer.2004.10.033.

[9] M. Lin, P. Xu, W. Zhong, Preparation, characterization, and release behavior of aspirin-loaded poly(2-hydroxyethyl acrylate)/silica hydrogels, J. Biomed. Mater. Res. Part B Appl. Biomater. 100B (2012) 1114-1120. doi:10.1002/jbm.b.32678.

[10] S. Manzano, S. Poveda-Reyes, G.G. Ferrer, I. Ochoa, M. Hamdy Doweidar, Computational analysis of cartilage implants based on an interpenetrated polymer network for tissue repairing, Comput. Methods Programs Biomed. 116 (2014) 249259. doi:10.1016/j.cmpb.2014.06.001.

[11] M. Lück, B.R. Paulke, W. Schröder, T. Blunk, R.H. Müller, Analysis of plasma protein adsorption on polymeric nanoparticles with different surface characteristics., J. Biomed. Mater. Res. 39 (1998) 478-85. doi:10.1002/(SICI)10974636(19980305)39:3<478::AID-JBM19>3.0.CO;2-6.

[12] A. Arun, B.S.R. Reddy, In vitro drug release studies from the polymeric hydrogels based on HEA and HPMA using 4\{(E)-[(3Z)-3-(4-(acryloyloxy)benzylidene)-2-hexylidene]methyl\}phenyl acrylate as a crosslinker, Biomaterials. 26 (2005) 1185-1193. doi:10.1016/j.biomaterials.2004.04.023.

[13] Y. Chan, T. Wong, F. Byrne, M. Kavallaris, V. Bulmus, Acid-labile core cross-linked micelles for pH-triggered release of antitumor drugs, Biomacromolecules. 9 (2008) 1826-1836. doi:10.1021/bm800043n.

[14] O. V. Khutoryanskaya, Z.A. Mayeva, G.A. Mun, V. V. Khutoryanskiy, Designing temperature-responsive biocompatible copolymers and hydrogels based on 2-hydroxyethyl(meth)acrylates, Biomacromolecules. 9 (2008) 3353-3361. doi:10.1021/bm8006242.

[15] K. McAllister, P. Sazani, M. Adam, M.J. Cho, M. Rubinstein, R.J. Samulski, J.M. DeSimone, Polymeric Nanogels Produced via Inverse Microemulsion Polymerization as Potential Gene and Antisense Delivery Agents, J. Am. Chem. 
Soc. 124 (2002) 15198-15207. doi:10.1021/ja027759q.

[16] C. Martínez-Ramos, S. Lainez, F. Sancho, M.A. García Esparza, R. Planells-Cases, J.M. García Verdugo, J.L. Gómez Ribelles, M. Salmerón Sánchez, M. Monleón Pradas, J.A. Barcia, J.M. Soria, Differentiation of Postnatal Neural Stem Cells into Glia and Functional Neurons on Laminin-Coated Polymeric Substrates, Tissue Eng. Part A. 14 (2008) 13651375. doi:10.1089/ten.tea.2007.0295.

[17] A. Vallés Lluch, A. Campillo Fernández, G. Gallego Ferrer, M. Monleón Pradas, Bioactive scaffolds mimicking natural dentin structure, J. Biomed. Mater. Res. Part B Appl. Biomater. 90B (2008) 182-194. doi:10.1002/jbm.b.31272.

[18] A. Lerf, H. He, M. Forster, J. Klinowski, Structure of Graphite Oxide Revisited, J. Phys. Chem. B. 102 (1998) 4477-4482. doi:10.1021/jp9731821.

[19] D.W. Boukhvalov, M.I. Katsnelson, Modeling of Graphite Oxide Modeling of Graphite Oxide, 130 (2008) 10697-10701. doi:10.1021/ja8021686.

[20] D. Konios, M.M. Stylianakis, E. Stratakis, E. Kymakis, Dispersion behaviour of graphene oxide and reduced graphene oxide, J. Colloid Interface Sci. 430 (2014) 108-112. doi:10.1016/j.jcis.2014.05.033.

[21] H. Pandey, V. Parashar, R. Parashar, R. Prakash, P.W. Ramteke, A.C. Pandey, Controlled drug release characteristics and enhanced antibacterial effect of graphene nanosheets containing gentamicin sulfate, Nanoscale. 3 (2011) 4104. doi:10.1039/c1nr10661a.

[22] S. Liu, T.H. Zeng, M. Hofmann, E. Burcombe, J. Wei, R. Jiang, J. Kong, Y. Chen, Antibacterial Activity of Graphite, Graphite Oxide, Graphene Oxide, and Reduced Graphene Oxide: Membrane and Oxidative Stress, ACS Nano. 5 (2011) 6971-6980. doi:10.1021/nn202451x.

[23] W. Hu, C. Peng, W. Luo, M. Lv, X. Li, D. Li, Q. Huang, C. Fan, Graphene-Based Antibacterial Paper, ACS Nano. 4 (2010) 4317-4323. doi:10.1021/nn101097v.

[24] C.M. Santos, J. Mangadlao, F. Ahmed, A. Leon, R.C. Advincula, D.F. Rodrigues, Graphene nanocomposite for biomedical applications: fabrication, antimicrobial and cytotoxic investigations, Nanotechnology. 23 (2012) 395101. doi:10.1088/0957-4484/23/39/395101.

[25] H.N. Lim, N.M. Huang, C.H. Loo, Facile preparation of graphene-based chitosan films: Enhanced thermal, mechanical and antibacterial properties, J. Non. Cryst. Solids. 358 (2012) 525-530. doi:10.1016/j.jnoncrysol.2011.11.007.

[26] S. Some, S.M. Ho, P. Dua, E. Hwang, Y.H. Shin, H. Yoo, J.S. Kang, D.K. Lee, H. Lee, Dual functions of highly potent graphene derivative-poly-l-lysine composites to inhibit bacteria and support human cells, ACS Nano. 6 (2012) 71517161. doi:10.1021/nn302215y.

[27] B.D. Ratner, A.S. Hoffman, F.J. Schoen, J.E. Lemons, Biomaterials science: an introduction to materials in medicine, 2004.

[28] J. Liang, Y. Huang, L. Zhang, Y. Wang, Y. Ma, T. Cuo, Y. Chen, Molecular-level dispersion of graphene into poly(vinyl alcohol) and effective reinforcement of their nanocomposites, Adv. Funct. Mater. 19 (2009) $2297-2302$. doi:10.1002/adfm.200801776.

[29] D. Han, L. Yan, W. Chen, W. Li, Preparation of chitosan/graphene oxide composite film with enhanced mechanical strength in the wet state, Carbohydr. Polym. 83 (2011) 653-658. doi:10.1016/j.carbpol.2010.08.038.

[30] X. Yang, Y. Tu, L. Li, S. Shang, X.M. Tao, Well-dispersed chitosan/graphene oxide nanocomposites, ACS Appl. Mater. Interfaces. 2 (2010) 1707-1713. doi:10.1021/am100222m.

[31] H.J. Salavagione, M.A. Gómez, G. Martínez, Polymeric modification of graphene through esterification of graphite oxide 
and poly(vinyl alcohol), Macromolecules. 42 (2009) 6331-6334. doi:10.1021/ma900845w.

[32] Z. Xu, C. Gao, In situ polymerization approach to graphene-reinforced nylon-6 composites, Macromolecules. 43 (2010) 6716-6723. doi:10.1021/ma1009337.

[33] D.D. Kulkarni, I. Choi, S.S. Singamaneni, V. V. Tsukruk, Graphene Oxide-Polyelectrolyte Nanomembranes, ACS Nano. 4 (2010) 4667-4676. doi:10.1021/nn101204d.

[34] C. Bao, Y. Guo, L. Song, Y. Hu, Poly(vinyl alcohol) nanocomposites based on graphene and graphite oxide: a comparative investigation of property and mechanism, J. Mater. Chem. 21 (2011) 13942. doi:10.1039/c1jm11662b. Y.S. Yun, Y.H. Bae, D.H. Kim, J.Y. Lee, I.J. Chin, H.J. Jin, Reinforcing effects of adding alkylated graphene oxide to polypropylene, Carbon N. Y. 49 (2011) 3553-3559. doi:10.1016/j.carbon.2011.04.055.

[36] J. Gao, F. Chen, K. Wang, H. Deng, Q. Zhang, H. Bai, Q. Fu, A promising alternative to conventional polyethylene with poly(propylene carbonate) reinforced by graphene oxide nanosheets, J. Mater. Chem. 21 (2011) 17627. doi:10.1039/c1jm14300j.

[37] J.-Y. Wang, S.-Y. Yang, Y.-L. Huang, H.-W. Tien, W.-K. Chin, C.-C.M. Ma, Preparation and properties of graphene oxide/polyimide composite films with low dielectric constant and ultrahigh strength via in situ polymerization, J. Mater. Chem. 21 (2011) 13569. doi:10.1039/c1jm11766a.

[38] N.D. Luong, U. Hippi, J.T. Korhonen, A.J. Soininen, J. Ruokolainen, L.-S. Johansson, J.-D. Nam, L.H. Sinh, J. Seppälä, Enhanced mechanical and electrical properties of polyimide film by graphene sheets via in situ polymerization, Polymer (Guildf). 52 (2011) 5237-5242. doi:10.1016/j.polymer.2011.09.033.

[39] D. Liu, Q. Bian, Y. Li, Y. Wang, A. Xiang, H. Tian, Effect of oxidation degrees of graphene oxide on the structure and properties of poly (vinyl alcohol) composite films, Compos. Sci. Technol. 129 (2016). doi:10.1016/j.compscitech.2016.04.004.

[40] S. Hassanzadeh, K.H. Adolfsson, D. Wu, M. Hakkarainen, Supramolecular Assembly of Biobased Graphene Oxide Quantum Dots Controls the Morphology of and Induces Mineralization on Poly(e-caprolactone) Films, Biomacromolecules. 17 (2016) 256-261. doi:10.1021/acs.biomac.5b01339.

[41] Y. Zhu, H. Wang, J. Zhu, L. Chang, L. Ye, Nanoindentation and thermal study of polyvinylalcohol/graphene oxide nanocomposite film through organic/inorganic assembly, Appl. Surf. Sci. 349 (2015) 27-34. doi:10.1016/j.apsusc.2015.04.204.

[42] S. Ramazani, M. Karimi, Aligned poly(e-caprolactone)/graphene oxide and reduced graphene oxide nanocomposite nanofibers: Morphological, mechanical and structural properties, Mater. Sci. Eng. C. 56 (2015) 325-334. doi:10.1016/j.msec.2015.06.045.

[43] J. Song, H. Gao, G. Zhu, X. Cao, X. Shi, Y. Wang, The preparation and characterization of polycaprolactone/graphene oxide biocomposite nanofiber scaffolds and their application for directing cell behaviors, Carbon N. Y. 95 (2015) 10391050. doi:10.1016/j.carbon.2015.09.011.

[44] H.J. Yoo, S.S. Mahapatra, J.W. Cho, High-speed actuation and mechanical properties of graphene-incorporated shape memory polyurethane nanofibers, J. Phys. Chem. C. 118 (2014) 10408-10415. doi:10.1021/jp500709m.

[45] A.M. Pinto, J. Cabral, D.A.P. Tanaka, A.M. Mendes, F.D. Magalhães, Effect of incorporation of graphene oxide and graphene nanoplatelets on mechanical and gas permeability properties of poly(lactic acid) films, Polym. Int. 62 (2013) 3340. doi:10.1002/pi.4290.

[46] Y. Li, J. Zhu, S. Wei, J. Ryu, L. Sun, Z. Guo, Poly(propylene)/graphene nanoplatelet nanocomposites: Melt rheological 
behavior and thermal, electrical, and electronic properties, Macromol. Chem. Phys. 212 (2011) 1951-1959. doi:10.1002/macp.201100263.

H. Bin Zhang, W.G. Zheng, Q. Yan, Y. Yang, J.W. Wang, Z.H. Lu, G.Y. Ji, Z.Z. Yu, Electrically conductive polyethylene terephthalate/graphene nanocomposites prepared by melt compounding, Polymer (Guildf). 51 (2010) 1191-1196. doi:10.1016/j.polymer.2010.01.027.

[48] O.M. Istrate, K.R. Paton, U. Khan, A. O’Neill, A.P. Bell, J.N. Coleman, Reinforcement in melt-processed polymergraphene composites at extremely low graphene loading level, Carbon N. Y. 78 (2014). doi:10.1016/j.carbon.2014.06.077.

[49] A. Tewatia, J. Hendrix, Z. Dong, M. Taghon, S. Tse, G. Chiu, W.E. Mayo, B. Kear, T. Nosker, J. Lynch, Characterization of melt-blended graphene - poly(ether ether ketone) nanocomposite, Mater. Sci. Eng. B Solid-State Mater. Adv. Technol. (2016) 1-9. doi:10.1016/j.mseb.2016.05.009.

[50] Y. Qian, Y. Lan, J. Xu, F. Ye, S. Dai, Fabrication of polyimide-based nanocomposites containing functionalized graphene oxide nanosheets by in-situ polymerization and their properties, Appl. Surf. Sci. 314 (2014) 991-999. doi:10.1016/j.apsusc.2014.06.130.

[51] R. Verdejo, M.M. Bernal, L.J. Romasanta, M. a. Lopez-Manchado, Graphene filled polymer nanocomposites, J. Mater. Chem. 21 (2011) 3301-3310. doi:10.1039/c0jm02708a.

[52] M.M. Zhang, H.X. Yan, C. Gong, T.T. Li, Hyperbranched polysiloxane functionalized graphene oxide for dicyclopentadiene bisphenol dicyanate ester nanocomposites with high performance, Express Polym. Lett. 8 (2014) 413424. doi:10.3144/expresspolymlett.2014.45.

[53] D.C. Marcano, D. V. Kosynkin, J.M. Berlin, A. Sinitskii, Z. Sun, A. Slesarev, L.B. Alemany, W. Lu, J.M. Tour, Improved synthesis of graphene oxide, ACS Nano. 4 (2010) 4806-4814. doi:10.1021/nn1006368.

[54] Y. Li, D. Pan, S. Chen, Q. Wang, G. Pan, T. Wang, In situ polymerization and mechanical, thermal properties of polyurethane/graphene oxide/epoxy nanocomposites, Mater. Des. 47 (2013) 850-856. doi:10.1016/j.matdes.2012.12.077.

[55] Y. Lu, J. Hao, G. Xiao, H. Zhao, Z. Hu, T. Wang, In situ polymerization and performance of alicyclic polyimide/graphene oxide nanocomposites derived from 6FAPB and CBDA, Appl. Surf. Sci. 394 (2017) 78-86. doi:10.1016/j.apsusc.2016.10.062.

[56] F. Ren, G. Zhu, P. Ren, Y. Wang, X. Cui, In situ polymerization of graphene oxide and cyanate ester-epoxy with enhanced mechanical and thermal properties, Appl. Surf. Sci. 316 (2014) 549-557. doi:10.1016/j.apsusc.2014.07.159.

J.R. Potts, S.H. Lee, T.M. Alam, J. An, M.D. Stoller, R.D. Piner, R.S. Ruoff, Thermomechanical properties of chemically modified graphene/poly(methyl methacrylate) composites made by in situ polymerization, Carbon N. Y. 49 (2011) 26152623. doi:10.1016/j.carbon.2011.02.023.

[58] D. Depan, T.C. Pesacreta, R.D.K. Misra, The synergistic effect of a hybrid graphene oxide-chitosan system and biomimetic mineralization on osteoblast functions, Biomater. Sci. 2 (2014) 264. doi:10.1039/c3bm60192g.

[59] Y.-H. Yu, Y.-Y. Lin, C.-H. Lin, C.-C. Chan, Y.-C. Huang, High-performance polystyrene/graphene-based nanocomposites with excellent anti-corrosion properties, Polym. Chem. 5 (2014) 535-550. doi:10.1039/C3PY00825H.

[60] D. Depan, R.D.K. Misra, The interplay between nanostructured carbon-grafted chitosan scaffolds and protein adsorption on the cellular response of osteoblasts: Structure-function property relationship, Acta Biomater. 9 (2013) 6084-6094. doi:10.1016/j.actbio.2012.12.019.

[61] H.K.F. Cheng, N.G. Sahoo, Y.P. Tan, Y. Pan, H. Bao, L. Li, S.H. Chan, J. Zhao, Poly(vinyl alcohol) nanocomposites filled with poly(vinyl alcohol)-grafted graphene oxide, ACS Appl. Mater. Interfaces. 4 (2012) 2387-2394. 
doi:10.1021/am300550n.

[62] Y. Chen, L. Chen, H. Bai, L. Li, Graphene oxide-chitosan composite hydrogels as broad-spectrum adsorbents for water purification, J. Mater. Chem. A. 1 (2013). doi:10.1039/c2ta00406b.

[63] X. Ma, Y. Li, W. Wang, Q. Ji, Y. Xia, Temperature-sensitive poly(N-isopropylacrylamide)/graphene oxide nanocomposite hydrogels by in situ polymerization with improved swelling capability and mechanical behavior, Eur. Polym. J. 49 (2013) 389-396. doi:10.1016/j.eurpolymj.2012.10.034.

[64] A. Usman, Z. Hussain, A. Riaz, A.N. Khan, Enhanced mechanical, thermal and antimicrobial properties of poly(vinyl alcohol)/graphene oxide/starch/silver nanocomposites films, Carbohydr. Polym. $153 \quad$ (2016) 592-599. doi:10.1016/j.carbpol.2016.08.026.

[65] Z. Sui, X. Zhang, Y. Lei, Y. Luo, Easy and green synthesis of reduced graphite oxide-based hydrogels, Carbon N. Y. 49 (2011) 4314-4321. doi:10.1016/j.carbon.2011.06.006.

[66] H. Huang, P. Chen, X. Zhang, Y. Lu, W. Zhan, Edge-to-edge assembled graphene oxide aerogels with outstanding mechanical performance and superhigh chemical activity, Small. 9 (2013) 1397-1404. doi:10.1002/smll.201202965.

[67] H. Huang, S. Lü, X. Zhang, Z. Shao, Glucono- $\delta$-lactone controlled assembly of graphene oxide hydrogels with selectively reversible gel-sol transition, Soft Matter. 8 (2012) 4609. doi:10.1039/c2sm25090j.

[68] T. Jiang, Z.-Y. Sui, Q.-S. Yang, X. Zhang, B.-H. Han, Preparation and characterization of a composite hydrogel with graphene oxide as an acid catalyst., Soft Matter. 11 (2015) 3215-21. doi:10.1039/c5sm00142k.

[69] H.L. Frisch, “Diffusion in polymers” edited by J. Crank and G. S. Park, Academic Press, London and New York, 1968; 452 pg, J. Appl. Polym. Sci. 14 (1970) 1657. doi:10.1002/app.1970.070140623.

[70] T. Szabó, O. Berkesi, I. Dékány, DRIFT study of deuterium-exchanged graphite oxide, Carbon N. Y. 43 (2005) 31863189. doi:10.1016/j.carbon.2005.07.013.

[71] C. Hontoria-Lucas, A.J. López-Peinado, J. d. D. López-González, M.L. Rojas-Cervantes, R.M. Martín-Aranda, Study of oxygen-containing groups in a series of graphite oxides: Physical and chemical characterization, Carbon N. Y. 33 (1995) 1585-1592. doi:10.1016/0008-6223(95)00120-3.

[72] G.I. Titelman, V. Gelman, S. Bron, R.L. Khalfin, Y. Cohen, H. Bianco-Peled, Characteristics and microstructure of aqueous colloidal dispersions of graphite oxide, Carbon N. Y. 43 (2005) 641-649. doi:10.1016/j.carbon.2004.10.035.

[73] G. Goncalves, P.A.A.P. Marques, C.M. Granadeiro, H.I.S. Nogueira, M.K. Singh, J. Grácio, Surface Modification of Graphene Nanosheets with Gold Nanoparticles: The Role of Oxygen Moieties at Graphene Surface on Gold Nucleation and Growth, Chem. Mater. 21 (2009) 4796-4802. doi:10.1021/cm901052s.

[74] H. Yang, F. Li, C. Shan, D. Han, Q. Zhang, L. Niu, A. Ivaska, Covalent functionalization of chemically converted graphene sheets via silane and its reinforcement, J. Mater. Chem. 19 (2009) 4632. doi:10.1039/b901421g.

[75] S. Wang, Y. Zhang, N. Abidi, L. Cabrales, Wettability and Surface Free Energy of Graphene Films, Langmuir. 25 (2009) 11078-11081. doi:10.1021/la901402f.

[76] J.L. Gomez-Ribelles, M. Monleon Pradas, G. Gallego Ferrer, N. Peidro Torres, V. Perez Gimenez, P. Pissis, A. Kyritsis, Poly ( methyl acrylate )/ Poly ( hydroxyethyl acrylate ) Sequential Interpenetrating Polymer Networks . Miscibility and Water Sorption Behavior, J. Polym. Sci. Part B Polym. Phys. 37 (1999) 1587-1599. 